1

2

3

4

13

14 Short title: Chromosomal inversions in passerine birds

Friday, May 6, 2016

12

\section{Range Overlap Drives Chromosome Inversion Fixation in Passerine Birds}

Daniel M. Hooper ${ }^{1,2}$

${ }^{1}$ Commitee on Evolutionary Biology, University of Chicago, Chicago, Illinois 60637

2 E-mail: dhooper1@uchicago.edu 
15 Chromosome inversions evolve frequently but the reasons why remain largely enigmatic. I

16 used cytological descriptions of 410 species of passerine birds (order Passeriformes) to

17 identify pericentric inversion differences between species. Using a new fossil-calibrated

18 phylogeny I examine the phylogenetic, demographic, and genomic context in which these

19 inversions have evolved. The number of inversion differences between closely related

20 species was highly variable yet consistently predicted by a single factor: whether the

21 ranges of species overlapped. This observation holds even when the analysis is restricted

22 to sympatric sister pairs known to hybridize, and which have divergence times estimated

23 similar to allopatric pairs. Inversions were significantly more likely to have fixed on a sex

24 chromosome than an autosome yet variable mutagenic input alone (by chromosome size,

25 map length, GC content, or repeat density) cannot explain the differences between

26 chromosomes in the number of inversions fixed. Together, these results support a model in

27 which inversions in passerines are adaptive and spread by selection when gene flow occurs

28 before reproductive isolation is complete.

31 KEY WORDS: Birds, chromosome inversion, gene flow, hybridization, passerines, 


\section{Introduction}

34 Speciation occurs not just from the accumulation of molecular changes in DNA composition

35 but also with physical rearrangements to the structure of diverging genomes. Chromosome

36 inversions, one common type of chromosomal rearrangement, are often observed as fixed

37 differences between species and as polymorphisms segregating within species [1,2].

38 Chromosome inversions are thought to impact sex chromosome evolution [3-5], supergene

39 formation [6-9], local adaptation [10-13], and reproductive isolation [14-18]. Despite

40 their potential evolutionary importance, the widespread presence of inversions is puzzling,

41 as new rearrangements may be initially disfavored due to structural underdominance in

42 heterokaryotypes, if crossing over within the inverted region during meiosis results in the

43 production of aneuploid gametes $[1,2,19]$. Reconciling the pervasiveness of chromosome

44 inversions both between and within species with possible selective disadvantages that a

45 new inversion faces remains an unresolved problem.

46 Traditional models of inversion fixation rely upon genetic drift acting within highly

47 structured populations to lift an inversion above $50 \%$ frequency in a deme, after which

48 selection favors its spread [20-24]. This model predicts that inversion fixation should be

49 independent of population size [20]. Hooper and Price [25] tested this in the Estrildid

50 finches (family Estrildidae) and rejected it, based on the strong positive relationship

51 observed between the rate of inversion fixation and range size. Other models of inversion

52 fixation have focused on selection, in which drift plays no part. An inversion may be

53 adaptive and spread (1) if its breakpoints favorably alter gene expression [26,27] or (2) by

54 meiotic drive if it happens to link alleles that together alter segregation distortion $[28,29]$.

55 Alternatively, recent models emphasize the contextual selective advantage of an inversion 
56 if it suppresses recombination [30-32]. In these scenarios, an inversion will spread when

57 natural selection favors the maintenance of linkage disequilibrium between sets of alleles

58 that are locally adapted to (3A) the habitat or (3B) the genetic background of a population

59 that would otherwise be broken up by recombination.

The alternative selection models make different predictions that can be tested with comparative analyses. All adaptive models depend on mutational input, which should scale

62 with population size, but selection pressures arising from breakpoint effects and meiotic

63 drive models should be particularly strongly associated with mutational input. This is

64 because selection pressures are less dependent on environmental context and mutations

65 that produce favorable effects are likely to be rare. Hence, these models predict a strong

66 scaling with population size. On the other hand, in recombination suppression models gene

67 flow plays a central role, as it generates the selective advantage for a new inversion. In one

68 case (hypothesis $3 \mathrm{~A}$, above), ecological differences are essential if local adaptation is to

69 create a selective advantage for an inversion [31]. Ecological differences can be assessed by

70 measuring characteristics such as body mass, feeding guild, habitat associations, etc. Gene

71 flow in the form of hybridization between incompletely reproductively isolated forms is

72 required if inversions are to increase in response to genetic incompatibilities (hypothesis

73 3B). This latter model therefore predicts partially reproductively isolated forms should

74 have had the potential to interbreed.

In Estrildidae, a previous analysis showed that both range size and range overlap

76 were positively associated with the rate of inversion fixation [25]. However, range size and

77 range overlap were themselves correlated, and it was difficult to disentangle their

78 contributions, given the sample size ( $\mathrm{N}=32$ species). The range size of a species may be 
79 considered an estimate of population size, predicted to be a strong correlate in the

80 breakpoint and meiotic drive models. Range overlap between closely related species

81 indicates the potential for hybridization, predicted to be essential in genetic incompatibility

82 models. The distinction between the two range effects is important as it suggests

83 alternative adaptive roles for chromosome inversions: range overlap implies that inversion

84 evolution may be intimately linked to the speciation process through interspecific

85 interactions (3B), but without range overlap this is not possible.

The Passeriformes are just one of 39 extant orders of birds yet comprise over half of

87 all avian biodiversity with the $\sim 6000$ species found in nearly every terrestrial habitat on

88 the planet [33]. The rapid rate of speciation and geographic expansion in passerines is

89 coupled with extensive eco-morphological diversification: body size varies $>350$-fold

90 between the smallest and largest species ( $4.2 \mathrm{~g}$ to $1,500 \mathrm{~g}$ ) while variation in beak shape

91 and behavior has produced a wide spectrum of feeding morphologies (nectarivores,

92 granivores, insectivores, frugivores, etc. [33,34]). In contrast to the wealth of eco-

93 morphological diversity in passerines, the gross structure of the passerine genome does

94 not vary greatly, with diploid chromosome number (2N) falling between $76-80$ for $77 \%$ of

95 species (Table S1; reviewed in [35]). Although inter-chromosomal rearrangements like

96 chromosome fusions, fissions, and translocations may be generally rare in birds, inversions

97 are far more common [25,35-38]. Cytological evidence for the frequent occurrence of

98 inversions in birds is corroborated by recent genomic studies that observe hundreds of

99 inversion-derived rearrangements between species [39-45].

100 In order to evaluate support for alternative models of inversion fixation, I here use

101 the phylogenetic and genomic distribution of large pericentric inversions (i.e. those 
102 encompassing the centromere) identified from the cytological literature of 410 species of

103 passerine birds. To this end, I build a fossil-calibrated phylogeny of those passerines with

104 karyotype data and map pericentric inversion fixation on the 9 largest autosomes and both

105 sex chromosomes (S1-4 Tables). I compare the extent of inversion differentiation, across

10680 passerine clades and 47 sister species pairs, with differences between species in range

107 size and their patterns of range overlap (S5-7 Tables). I evaluate the importance of raw

108 mutagenic input on the genomic distribution of inversions by assessing how the number of

109 inversions on a chromosome is associated with its size, map length, repeat density, and GC

110 content or whether it was an autosome or sex chromosome (S8-9 Tables). By examining

111 the drivers of chromosome inversion evolution in a group as species rich and ecologically

112 diverse as the passerines, I aim to illuminate both the frequency with which inversions

113 occur in birds and the implications for chromosome inversions and speciation with gene

114 flow, broadly.

\section{Results}

\section{Phylogenetic Signal of Chromosome Inversion Evolution in Passerines}

118 The time-calibrated phylogeny for the 410 karyotyped passerine species in this study is

119 shown in Figure 1 with family memberships labeled (see also S1-2 Figs.). The topology is

120 congruent both between and within families to previously published studies in

121 Passeriformes (S5 Table). Divergence time estimates between families are consistent again

122 with recent phylogenomic studies of crown Aves that utilized partially overlapping fossil

123 sets and similar calibration methods [46,47]. 
125 Fig 1. Pericentric inversion fixation rate variation across Passeriformes. Passerine

126 families included in this study are shown on the left: numbers within parentheses refer to

127 the number of karyotyped species and number of pericentric inversions within each family,

128 respectively. Families are ordered clockwise by phylogenetic position in the tree. The time-

129 dated phylogeny for the 410 karyotyped species used in this study is shown on the right.

130 Branches are color-coded according to the inferred rate of pericentric inversion fixation

131 using the R package ggtree [48] with rates partitioned according to the Jenks natural

132 breaks method where variance within bins is minimized, while variance between bins is

133 maximized [49].

134

135

The rate of inversion fixation averaged across all 410 passerine species was one

136 inversion every 5.3 million years of evolution along a branch (4269My total branch

137 length/808 inferred inversions). Inversion fixation rate varied greatly across lineages (Fig.

138 1). Rates ranged from no inversions fixed over $23.7 \mathrm{My}$ on the lineage leading to the

139 common iora (Aegithina tiphia) to an inversion on the $6^{\text {th }}$ largest autosome that separated

140 the pied and black-eared wheatear (Oenanthe pleschanka and O. melanoleuca) with a

141 divergence time of $\sim 0.2 \mathrm{Ma}$. Explaining the underlying evolutionary basis of this rate

142 variation was the guiding motivation of this study.

144 Inversion Differentiation Across 80 Passerine Clades

145 Analysis of inversion fixation using 80 independent passerine clades strongly suggests that

146 time and range overlap - rather than range size - are the best predictors of pericentric

147 inversion evolution in Passeriformes. The best model to predict the number of inversions 
148 fixed in each clade contained two variables (branch length and range overlap; S9 Table).

149 The two top models had similar AICc scores and model weights ( $\triangle$ AICc $<2$; S9 Table) so I

150 used model averaging to combine them into a final model (Table 1). This averaged model

151 included median clade range size as an additional parameter, however only branch length

$152(\mathrm{p}<0.0001)$ and range overlap were significant $(\mathrm{p}<0.0001$; Table 1). Older clades with

153 more sympatric species have significantly more inversions than younger and more

154 allopatric clades (Fig. 2; Table 1) and neither range size nor division of clades by ecological

155 niche contributed (S9 Table) Results were consistent regardless of whether I used a more

156 relaxed $\triangle \mathrm{AICc}$ cutoff to model averaging (i.e. averaging all models with $\triangle \mathrm{AICc}<4$ ) or an

157 alternative minimum range overlap cutoff values (10\% or $15 \%$ pairwise range overlap) to

158 calculate the extent of range overlap in each clade.

159

160 Table 1. Final averaged model for clade level analysis. Phylogenetic least squares

161 model to predict the number of pericentric inversions fixed in 80 passerine clades.

162 Approximate 95\% confidence intervals were calculated as the parameter estimate $+/-2 \times$

163 standard error. P values for parameter significance were calculated? by MuMIn in R [50]

164 model averaging the top two models with $\Delta \mathrm{AICc}<2$.

\begin{tabular}{lccccc}
\hline Parameter & Estimate & $\begin{array}{c}\text { Standard } \\
\text { Error }\end{array}$ & $\begin{array}{c}\text { Approximate } \\
\text { 95\% confidence } \\
\text { interval }\end{array}$ & $\boldsymbol{Z}$ & $\boldsymbol{P}$ \\
\hline (Intercept) & 0.14 & 0.76 & -1.37 to 1.66 & 0.19 & 0.87 \\
Branch length & 0.74 & 0.13 & 0.48 to 1.00 & 5.69 & $<2 \times 10^{-16}$ \\
Range overlap & 1.88 & 0.47 & 0.94 to 2.84 & 3.93 & $8.5 \times 10^{-5}$ \\
Range size & 0.18 & 0.10 & -0.02 to 0.38 & 1.77 & 0.08 \\
\hline
\end{tabular}

165

166 Fig 2. Pericentric inversion fixation rate variation across 80 passerine clades.

167 Fixation rate is shown against the proportion of sympatric species pairs (left) and median 
168 clade range size (right). Fixation rate calculated as the total number of inversions on all

169 chromosomes divided by the total clade branch length summed across each chromosome.

170 Each clade is represented by a circle and shaded according to the proportion of total

171 species with karyotype data.

172

173

174 Inversion Differentiation Across 47 Sister Species Pairs

175 As a complement to the clade level analysis, I considered sister pairs, as clearly

176 independent points. Sympatric sister species were significantly more likely to differ by an

177 inversion than allopatric sisters (two-tailed $t$-test: $t_{45}=3.1, \mathrm{p}=0.003$; Fig. $3 \mathrm{~A}$ ). The best

178 model to explain the number of inversion differences between sister species contained a

179 single parameter: whether sister species overlapped in range or not (Fig. 3B; S9 Table). The

180 two top models had similar AICc scores and model weights ( $\triangle$ AICc $<2$; S9 Table) so I used

181 model averaging to combine them into a final model (Table 2). While this averaged model

182 included sister pair age as an additional parameter, only range overlap was found to be

183 significant $(\mathrm{p}=0.01$; Tables 2,3$)$. The 12 sister species known to hybridize in nature were

184 more likely to be differentiated by an inversion than their allopatric counterparts (two-

185 tailed $t$-test: $t_{21}=3.0, \mathrm{p}=0.007$; Fig. $\left.3 \mathrm{~A}\right)$ despite not being genetically more divergent $\left(t_{21}=\right.$

$186 \quad 0.28, \mathrm{p}>0.1 ;$ S6 Table).

187

188 Table 2. Final averaged model for sister species analysis. Generalized linear model

189 with Poisson errors to predict the number of pericentric inversion differences between 47

190 sister species pairs. Approximate 95\% confidence intervals were calculated as the 
191 parameter estimate $+/ .2 \times$ standard error. P values for parameter significance were

192 calculated? by MuMIn in R [50] after model averaging the top two models with $\Delta$ AICc $<2$.

\begin{tabular}{lccccc}
\hline Parameter & Estimate & $\begin{array}{c}\text { Standard } \\
\text { Error }\end{array}$ & $\begin{array}{c}\text { Approximate } \\
\text { 95\% confidence } \\
\text { interval }\end{array}$ & $\boldsymbol{Z}$ & $\boldsymbol{P}$ \\
\hline $\begin{array}{l}\text { (Intercept) } \\
\text { Range overlap }\end{array}$ & -0.54 & 0.23 & -1.0 to -0.08 & 2.31 & 0.021 \\
(Yes) & 0.67 & 0.25 & 0.17 to 1.17 & 2.57 & 0.01 \\
Sister age & 0.08 & 0.10 & -0.12 to 0.28 & 0.77 & 0.44 \\
\hline
\end{tabular}

194 Table 3. Pericentric inversion differentiation between sister species. Species pairs

195 binned by range overlap (Allopatric versus Sympatric) and inversion presence (no

196 inversions or some inversions). The average value and range is shown for Age, Range Size,

197 and number of Inversion Differences. Both fixed inversion differences and inversion

198 polymorphisms observed in one sister but not the other were included. Full data in S5

199 Table.

\begin{tabular}{lccccc}
\hline $\begin{array}{c}\text { Sister } \\
\begin{array}{c}\text { Species } \\
\text { Distribution }\end{array}\end{array}$ & $\begin{array}{c}\text { Inversion } \\
\text { Presence }\end{array}$ & $\begin{array}{c}\text { Sister } \\
\text { Pairs (N) }\end{array}$ & Age (Ma) & $\begin{array}{c}\text { Range Size } \\
\mathbf{( 1 0 6}^{\mathbf{2} \mathbf{k m}^{2} \mathbf{)}}\end{array}$ & $\begin{array}{c}\text { Inversion } \\
\text { Differences }\end{array}$ \\
\hline Allopatric & None & 6 & $2.4(0.9-5.0)$ & $2.5(0.2-5.3)$ & 0 \\
& Some & 3 & $2.8(1.0-6.9)$ & $4.0(1.1-5.6)$ & $2.3(1-4)$ \\
Sympatric & None & 7 & $4.25(2.3-7.5)$ & $6.8(2.2-10.9)$ & 0 \\
& Some & 31 & $3.7(0.2-9.3)$ & $7.9(0.8-35.2)$ & $3.2(1-12)$
\end{tabular}

201 Fig 3. Pericentric inversion differentiation between sister species. Sister species

202 sorted into allopatric pairs, sympatric pairs (any amount of range overlap), and the subset

203 of sympatric sister pairs that are known to hybridize [51]. Variation between sister species

204 groups in A) the proportion of sister pairs with and without inversion differences (none or

205 some, respectively) and B) the number of inversion differences between sister species. 
Species triplets consist of a sister pair and an outgroup species, where the outgroup overlaps one of the two sisters but not the other. Comparisons of differences between the

209 outgroup and each sister therefore test for a role of sympatry, with time completely

210 factored out [52-54]. Figure 4 shows a representative example where the extent of

211 inversion differentiation is conditional upon geographic overlap with the outgroup. Results

212 form triplet comparison confirmed the importance of range overlap (S7 Table). A

213 conservative triplet set, where the outgroup shows no overlap with one of the sisters, has

214 little power $(\mathrm{N}=5)$ but the three triplets that show differences in the extent of inversion

215 accumulation all find that the sister species whose range overlapped with the outgroup had

216 accumulated more inversion differences. In a relaxed triplet set, in which some degree of

217 range overlap was allowed between the outgroup or sisters ( $\mathrm{N}=19), 7$ triplets showed no

218 difference in inversion differentiation. However, ten triplets showed more inversions in the

219 sister species that overlaps with the outgroup and 2 triplets the opposite pattern (two-

220 tailed sign rank test, $\mathrm{p}=0.039$ ). Differences in range size between sisters did not predict

221 the number of inversion differences (regression of contrasts, forced through the origin, $p>$

$2220.1)$.

224 Fig 4. Triplet analysis of pericentric inversion evolution across greenfinches in the

225 genus Chloris. The phylogenetic history of pericentric inversion fixation in Chloris is

226 shown on the left, with inversions (black ovals) on the branches they are inferred to have

227 fixed. The geographic distribution and likeness of each species is shown on the right. The 228 European greenfinch Chloris chloris (green, A) and black-headed greenfinch C. ambigua 
229 (red, B) are allopatric sister species. The grey-capped greenfinch C. sinica (blue, Out) is the

230 outgroup geographically isolated from C. chloris but in geographic contact with C. ambigua.

231 While 5 inversions have evolved to differentiate C. ambigua from C. sinica, only two

232 inversions have evolved that differentiate $C$. chloris from $C$. sinica - neither of which

233 occurred following the divergence between $C$. ambigua and C. chloris. ${ }^{*}$ I have treated the

234 three members of a black-headed greenfinch species complex (C. ambigua, C. monguilloti,

235 and $C$. spinoides) as a single species $C$. ambigua here based on the lack of any observed

236 premating isolation where their ranges overlap [51].

239 Genomic Distribution of Chromosome Inversions

240 The fastest rearranging autosomal chromosome evolved $4 \times$ faster than the slowest (Tables

2414 , S8). The three top models to explain the variation in inversion fixation rate between the

242 autosomes had nearly equivocal AICc scores and model weights ( $\triangle \mathrm{AICc}<2$; S10 Table). I

243 used model averaging to combine them into a final model that included only chromosome

244 GC content and repeat density (S10 Table). Of these, only repeat density was found to be

245 significant $(\mathrm{z}$ value $=2.3, \mathrm{p}=0.02 ; \mathrm{S} 10$ Table). The significance of the observed association

246 was not robust to model averaging the six top models with $\Delta$ AICc $<4$, suggesting only a

247 weak effect of repeat density (S10 Table). Inclusion of the Z chromosome in these analyses

248 further reduced the fit of any mutagenic model to explain variation in inversion fixation

249 rate between chromosomes. 
251 Table 4. Genomic distribution of pericentric inversions. Autosomes are listed in order

252 of descending size with their presumed homology to the collared flycatcher (Ficedula

253 albicollis) genome given in parentheses. Values for chromosome size and map length come

254 from the collared flycatcher genome [44] while GC content and repeat density come from

255 the zebra finch (Taeniopygia guttata) genome [55,56]. Variance in branch lengths by

256 chromosome reflects species with missing data.

\begin{tabular}{ccccccc}
\hline Chromosome & $\begin{array}{c}\text { Size } \\
\text { (Mb) }\end{array}$ & $\begin{array}{c}\text { Map Length } \\
\text { (cM) }\end{array}$ & $\begin{array}{c}\text { GC Content } \\
\text { (\%) }\end{array}$ & $\begin{array}{c}\text { Repeat } \\
\text { Density (\%) }\end{array}$ & $\begin{array}{c}\text { Branch } \\
\text { Length (My) }\end{array}$ & Inversions \\
\hline 1 (FAL2) & 157.4 & 320 & 39 & 0.38 & 4449.2 & 39 \\
2 (FAL1) & 119.8 & 245 & 39.2 & 0.23 & 4449.2 & 71 \\
3 (FAL3) & 115.7 & 230 & 39.4 & 0.38 & 4449.2 & 80 \\
4 (FAL1A) & 74.8 & 230 & 39.7 & 0.14 & 4449.2 & 108 \\
5 (FAL4) & 70.3 & 175 & 39.2 & 0.28 & 4437.3 & 104 \\
6 (FAL5) & 64.6 & 172 & 40.8 & 0.12 & 4398.1 & 79 \\
7 (FAL7) & 39.3 & 125 & 41.1 & 0.14 & 4242.1 & 48 \\
8 (FAL6) & 37.2 & 122 & 41.6 & 0.19 & 4088.8 & 35 \\
9 (FAL8) & 32 & 95 & 41.3 & 0.5 & 3973.8 & 23 \\
Z & $59.7^{*}$ & 165 & 39.2 & 1.5 & 4449.2 & 121 \\
W & 27 & & - & & 3387.8 & 100 \\
\hline
\end{tabular}

$257 \quad *$ The sizes of chromosomes are nearly identical between the collared flycatcher and the 258 zebra finch except for chromosome Z (59.7Mb vs. 74.6Mb, respectively).

261 the $\mathrm{Z}$ chromosome and $2.5 \times$ faster on the $\mathrm{W}$ chromosome (two-sample paired $t$-tests with

262 the 80 clades as replicates, ChrZ: $\mathrm{t}_{79}=2.2, \mathrm{p}=0.034$; ChrW: $\mathrm{t}_{74}=4.0, \mathrm{p}=1.0 \times 10^{-4}$ ). The W

263 chromosome carried more pericentric inversions than the $\mathrm{Z}$ (paired $t$-test: $\mathrm{t}_{74}=2.5, \mathrm{p}=$

264 0.013). When scaled by chromosome length, the difference on the W chromosome is more

265 dramatic with 3.7 inversions per Mb compared to 1.1 inversions per $\mathrm{Mb}$ on average for all

266 other chromosomes, including the $\mathrm{Z}$. The genomic distribution of segregating inversion

267 polymorphisms within species, as well as variants apparently fixed in different populations

268 of the same species, was also biased towards the sex chromosomes. Of the 43 within- 
species pericentric inversion variants identified from the cytological data, $14 \%$ were on the $\mathrm{Z}$ chromosome ( 6 of 43 variants) and $26 \%$ on the W chromosome (11 of 43 ; S2 Table).

\section{Discussion}

273 Large pericentric inversions have evolved often in passerine birds, with a minimum

274 estimate of one inversion for every 5.3 million years of evolution. This estimate does not

275 account for possible back-substitutions. Within 80 passerine clades, which include more

276 recent events only and so the influence of structural back mutations is minimized, the

277 average rate of pericentric inversion fixation for all chromosomes was one inversion fixed

278 every 3.9 million years, which approximates the rate at which measurable hybrid infertility

279 in birds appears [57], but ranged from no inversions fixed over the span of 27.7My (in the

280 family Dicruridae) to one inversion fixed over 1.2My (in the genus Chloris; S5 Table). Many

281 inversions have doubtless gone undetected. Twice as many individuals were karyotyped in

282 the 31 passerine species found to have inversions segregating versus the study as a whole

283 (9.9 versus 4.8 individuals, respectively; excluding 3 species of large sample size, Fig. 5; S2

284 Table). Moreover, as I have restricted my analysis to only those pericentric inversions large

285 enough to be detectable via cytological analysis (i.e. excluding small pericentric inversions

286 as well as all paracentrics) these counts are surely an underestimate of the true extent of

287 chromosome inversion variation in passerines, as has become clear from genomic studies

$288 \quad[44,45,58]$.

289

290 Fig 5. Natural log distribution of sample size for karyotyped species. The average

291 number of individuals karyotyped are indicated by arrows for all species (black arrow, 4.8 
292 indiv.) and species where structural variants were observed (red arrow, 9.9 indiv.) after

293 removing the three species where sampling effort was designed to study inversion

294 polymorphism [S1-2 Tables].

295

The main finding from this study is that the strongest correlate of inversion fixation

297 after accounting for time, is not range size, but range overlap. Variation in the number of

298 inversions observed across clades positively scales with the proportion of sympatric

299 species pairs each contains and sister species comparisons directly invoke range overlap as

300 an important correlate. Indeed, the evidence suggests that while rearrangements occur

301 more often in clades with larger ranges, thereby rejecting models based on drift and peak

302 shifts $[20,21,25]$, this effect is secondary to whether or not the ranges of these species are

303 sympatric. Range overlap is pertinent to one particular model of inversion spread in which

304 gene flow between partially reproductively isolated forms favors inversions, because F1

305 hybrids more rarely recombine parental allelic combinations in the inverted region

306 compared to collinear chromosomes. Altogether, the evidence suggests that pericentric

307 inversions in passerines are adaptive and derive their selective advantage by keeping sets

308 of locally adapted alleles together when gene flow between incipient species would

309 otherwise break them up. I first consider caveats before returning to the main results.

310 The first issue is whether sympatry generally reflects a historical capacity for gene

311 flow that is precluded by allopatry. While species with allopatric ranges may well have

312 been largely allopatric since they first split, species with sympatric distributions may have

313 become reproductively isolated before establishing secondary contact. Empirical evidence

314 across a broad spectrum of taxonomic groups, however, suggests otherwise. Secondary 
315 contact between incipient species has regularly been followed by hybridization and genetic

316 exchange (reviewed in [59]). We know for birds that complete postmating isolation in the

317 wild typically requires 3 My or more [37,60], with hybrid zones regularly forming between

318 taxa separated by that age ([60], S6 Table). This suggests that secondary contact often

319 precedes the completion of reproductive isolation and could often select for chromosome

320 inversion. Non-hybridizing sympatric pairs exhibit no discernible disparity in the extent of

321 inversion differentiation when compared to hybridizing pairs (Fig. 3; S6 Table).

The second issue is that allopatric sister species may exhibit reduced inversion

323 differentiation due to a lower mutational input because they are younger-less time for an

324 inversion mutation to occur-or because they have smaller population sizes-lower

325 inversion mutation rate per generation. However, I find no strong evidence that the

326 phenomenon of reduced inversion differentiation among allopatric species is primarily a

327 result of allopatric sister species tending to be younger and smaller in range than their

328 sympatric counterparts (Table 3). Analysis of species triplets, which entirely control for

329 age, also find no evidence that the extent of inversion differentiation between sister species

330 and an outgroup taxon is a result of differences in sister range size (S7 Table). Together

331 with the findings from hybridizing sister pairs, these results strongly suggest that range

332 overlap makes an important contribution to chromosome inversion fixation.

334 Evaluating Support for Alternative Models of Inversion Evolution

335 Four alternative models of inversion fixation were considered to explain the distribution of

336 pericentric inversions in passerines. First, in agreement with an earlier analysis [25], I find

337 that genetic drift is unlikely to have been a strong force. The fixation rate for inversions on 
338 all chromosome classes across the 80 passerine clades examined scales with body size

339 corrected range size (autosomes: $r=0.38$, chromosome $\mathrm{Z}: \mathrm{r}=0.32$, and chromosome W: $\mathrm{r}=$

$340 \quad 0.25$; S5 Table) while fixation rate by drift should, to a first approximation, be population-

341 size independent [20-22,25].

$342 \quad$ Assuming rates of evolution by breakpoint selection and meiotic drive models

343 should be largely dependent on mutagenic input, results do not support these models

344 either, because range size is not a strong correlate, and because of the distribution across

345 chromosomes (see below). Indeed, no mutagenic expectation of inversion fixation well

346 explained the genomic distribution of autosomal pericentric inversions across the 410

347 passerine species examined in this study (Tables $4, \mathrm{~S} 10$ ). These findings suggest that a

348 force beyond raw mutagenic input is responsible for heterogeneity in the extent of

349 pericentric inversion differentiation observed in passerines. Indeed, results are consistent

350 instead with an adaptive model in which an inversion has a selective advantage if it

351 maintains - through recombination suppression - the a) ecological or b) reproductive

352 differentiation of a population at risk of being homogenized by gene flow.

\section{Gene Flow and Chromosome Inversion Fixation}

355 The adaptive model of rearrangement evolution presented by Kirkpatrick and Barton [31]

356 relies on gene flow between ecologically differentiated populations to facilitate the spread

357 of an inversion. Under this model, an inversion that encompasses two or more loci carrying

358 alleles favored in the environmental background of a population may be favored if

359 recombination would otherwise break them up. One prediction is that species prone to

360 ecological speciation may be more likely to fix inversions first, because divergent selection 
361 on loci involved in local adaption is strong and second because diverging forms are more

362 likely to occur in sympatry, being ecologically differentiated, before postmating isolation is

363 complete [61]. For example, finch-like forms appear to speciate ecologically and achieve

364 sympatry more quickly than insectivores [61], so the model of local ecological adaptation

365 predicts finches should carry more inversion differences. While classifications of ecology in

366 this study were crude, feeding guild and inversion accumulation are not correlated (S7

367 Table). Future empirical efforts to examine the genic content and targets of selection within

368 inversions, like those in flies [62,63], mosquitoes [64], butterflies [6,12,65], sticklebacks

$369[13,66]$, and monkeyflowers $[11,18]$ will be more powerful ways to assess the degree to

370 which ecology has shaped the evolutionary trajectory of inversions in passerines.

In an extension of the local adaption model, hybridization between incipient species

372 creates a selective advantage for a chromosome inversion that maintains linkage between

373 loci locally adapted to the genetic backgrounds of hybridizing taxa. For example, alleles at

374 loci involved in pre- and/or postmating isolation are favored when kept in tight linkage by

375 an inversion because of the increased production of unfit hybrids when they recombine.

376 The likelihood of inversion differentiation under this model is expected to be most strongly

377 associated with the frequency with which gene flow is part of the speciation process. As

378 geographic isolation precludes hybridization, there is no selective advantage for a novel

379 inversion to capitalize on and species that achieve reproductive isolation in allopatry

380 should maintain chromosome co-linearity. This model has support from both clade and

381 sister species analyses.

382 Two extreme examples illustrate the case for a role of range overlap in inversion

383 fixation. First, tits (family Paridae) in the genera Periparus and Pardaliparus last shared a 
384 common ancestor 7Ma (5.2 - 8.9Ma, 95\% HPD), have largely allopatric distributions (no

385 pair of species overlap in range more than $20 \%$ ), and no known inversion differences. In

386 stark contrast, an Asian clade of tits in the genus Poecile diverged 4.3Ma (3.1 - 5.6Ma, 95\%

387 HPD), are largely sympatric (? of pairs), and the species examined differ by up to seven

388 pericentric inversions (S5 Table). Natural hybrids between Poecile montanus and $P$.

389 palustris have been recorded in the wild [51], more directly linking gene flow to inversion

390 evolution. A second example comes from greenfinches in the genus Chloris (family

391 Fringillidae, Fig. 4). Inversion differentiation between C. sinica and sympatric C. ambigua

392 has outpaced inversion differentiation between C. sinica and allopatric C. chloris (Fig. 4).

393 Further suggesting a positive interaction between gene flow and inversion evolution, $C$.

394 ambigua and C. sinica hybridize at low frequencies where their ranges overlap [51].

396 Genomic Distribution of Pericentric Inversions

397 The distribution of chromosome inversions detected using comparative genomic

398 approaches in birds is positively associated with chromosome size [44,45], and inversion

399 breakpoints are often located in regions with elevated recombination rates, GC content, and

400 repeat density [44]. These results were not replicated here. A primary reason for this

401 difference likely resides in the different size classes of inversions considered between

402 studies [25]. Inversions detected from comparing high-resolution linkage maps [44] or

403 whole genome alignments [45] are capable of finding structural variants orders of

404 magnitude smaller than the exclusively large inversions I identified from cytological data.

405 Indeed, the pericentric inversions considered here may be of greater evolutionary

406 relevance as they potentially come with both higher fitness costs and greater selective 
407 advantages than the more comprehensive set of inversions found in comparative genomic

408 surveys.

However, sex chromosomes do accumulate pericentric inversions more rapidly than

410 the autosomes (Tables 4, S8), despite having smaller population sizes. A quarter of all

411 identified inversion polymorphisms occur on the $\mathrm{W}$ chromosome while $14 \%$ are on the $\mathrm{Z}$

412 chromosome. The higher rate of sex chromosome inversion evolution could be considered

413 a consequence of sex chromosomes possessing a higher structural mutation rate; lower

414 fitness costs for structural rearrangements, a greater influence of genetic drift, or - in the

415 case of the $\mathrm{Z}$ chromosome - a greater fitness benefit to a recombination modifier. I find no

416 evidence for an influence of drift in governing variation in inversion fixation on any

417 chromosome or for a higher mutation rate on the $\mathrm{Z}$ compared to the autosomes. Inference

418 about the $\mathrm{W}$ chromosome is difficult as its features are not well understood. In contrast, a

419 recent study finds that positive selection is the driving force responsible for elevated rates

420 of functional differentiation observed for Z-linked genes in six species of Galloanserae [67].

421 These are ideal conditions for inversions on the $\mathrm{Z}$ chromosome to be favored as

422 recombination modifiers when differentiation occurs with gene flow. One route to further

423 understanding will come from explicit studies of the selective forces maintaining inversion

424 polymorphisms within species [7-9].

425

426 Materials and Methods

427 Identifying Inversions

428 I called chromosome inversions from classic studies of gross karyotype structure that

429 encompass nearly $8 \%$ of all passerine species and $>50 \%$ of passerine families. Of the 427 
430 passerine species that have had their karyotypes described, I discarded 15 because the

431 cytological data was not of sufficiently high quality to include in this study and two because

432 no suitable genetic data currently exists for them and no tissue materials were available. I

433 analyzed cytological data for the remaining 410 species, representing birds from 59

434 families (S1 Table). Data was sourced from 110 studies that span five decades of cytological

435 research (S1 Table). Methods utilized to describe karyotype varied from simple Giemsa

436 staining to fluorescent in situ hybridization with chromosome painting. Sampling rigor

437 varied across studies with respect to the number (average of 7 karyotyped individuals per

438 taxon, range from 1 to 432; Fig. 5) and sex representation of each species (data from both

439 males and females in 296 of 410 species; S1 Table). Sampling information was not given for

44029 species (S1 Table). Due to the considerable heterogeneity in the quality and quantity of

441 karyotype descriptions between species and studies, I focus on a simple yet powerful trait

442 with which to infer chromosome inversion differences between and within species:

443 centromere position.

444 For each species, I converted centromere position for the 9 largest autosomal

445 chromosomes and both sex chromosomes into character state data (S1 Table). I scored

446 each chromosome for approximate centromere position (i.e., whether they were

447 metacentric, sub-metacentric, sub-telocentric, or telocentric), following conventions

448 established by Levan et al. [68]. I identified homologous chromosomes between species by

449 a combination of their physical size, shared banding pattern, and matching chromosome

450 painting, as the information was available. I treated centromere position of a chromosome

451 as distinct when species shared the same general classification (e.g., both were sub-

452 metacentric) but the authors noted that the banding pattern flanking the centromere 
453 consistently differed. I only include pericentric inversions in my analyses as the cytological

454 data has far less power to identify paracentric inversions (those not encompassing the

455 centromere). Centromere repositioning can result from processes other than pericentric

456 inversion, such as the redistribution of heterochromatin $[69,70]$ and the evolution of neo-

457 centromeres [70,71]. I found no evidence, however, for either of these alternative

458 mechanisms of centromere repositioning in the 85 species with banding data available to

459 test for them as centromere movement was supported by inversion of proximal banding

460 patterns (Table S1).

461 While the distribution of fixed inversion differences can be used to infer historical

462 patterns of selection, the mechanisms of selection affecting inversions are best studied

463 when rearrangements still segregate in natural populations. I therefore evaluated all

464 species for the occurrence of pericentric inversion polymorphisms and for the presence of

465 inversions present in different parts of species ranges (S1-2 Tables). Polymorphisms

466 segregating within populations were often noted in the paper of interest, but the majority

467 of geographic variants are first reported in this study, as they generally depend on

468 comparing different published studies (S2 Table). Of the 50 total rearrangement

469 polymorphisms identified, two are likely a product of chromosome translocation and three

470 are shared between species - two across three species and one between two species (S2

471 Table).

472

473 Phylogenetic Analyses

474 In order to characterize the phylogenetic distribution of chromosome inversion fixation, I

475 built a time-dated phylogeny for the 410 passerine species with karyotype data available. I 
476 gathered sequence data from six genes: two mitochondrial: $c y t b$ and $N D 2$, and four nuclear:

477 myoglobin $(M G)$ exons 2-3, ornithine decarboxylase $(O D C)$ exons 6-8, beta-fibrinogen

478 (FIB5) exons 5-6, and recombination activating protein-1 (RAG1). Data were primarily

479 sourced from GenBank. For 12 karyotyped species with no or low sequence representation

480 I generated the data myself using standard methods (Table S3). Phylogenetic and dating

481 analyses were conducted using BEAST v1.8.2 [72]. Sequence data was partitioned by locus,

482 each with its own uncorrelated lognormal relaxed clock, and assigned the optimal-fit model

483 of sequence evolution estimated for each locus using jModelTest v0.1.1 [73]. The phylogeny

484 was time-calibrated using 20 fossil calibrations broadly dispersed both in time and

485 topology (S1 Fig.; S4 Table). This is, to my knowledge, the most extensive fossil calibration

486 effort to date within Passeriformes. Each fossil calibration was applied to its corresponding

487 node as a minimum age bound using a conservative uniform prior based on the age of the

488 fossil itself and 80Ma. I ran BEAST for 50 million generations and sampled every 5000 for a

489 total of 10,000 trees of which the first 1000 were discarded as burn in. I assessed run

490 length and appropriate sampling for each parameter using Tracer v1.6 [74]. Using

491 TreeAnnotator v1.7.2 [72], I extracted the maximum clade credibility tree, with associated

492 confidence intervals for median node heights (Figs. 2, S2).

494 Phylogenetic Distribution of Inversion Fixation

495 In order to map inversion evolution across the phylogeny, I estimated the ancestral

496 centromere position (up to 4 possible states: metacentric, sub-metacentric, sub-telocentric,

497 or telocentric) for each chromosome at each node in the tree by maximum likelihood in

498 Mesquite v2.7.5 [75]. I obtained the maximum likelihood estimate for each ancestral 
centromere position for each chromosome at every node. Inversions were inferred to have

500 occurred upon branches where the karyotype of an internal node differed from subsequent

501 nodes or the tips and was supported by a maximum likelihood, $\mathrm{p}>0.75$. I used this

502 phylogenetic representation of inversion evolution in passerines to investigate the drivers

503 of inversion fixation between species and within the genome. I conducted analyses at two

504 different phylogenetic levels. First I defined 80 clades comprising between 3 to 85 species

505 and, second, I used sister species pairs.

506

507 Chromosome Inversion Variation Between Clades

508 I partitioned the phylogeny of karyotyped taxa into 80 clades of closely related species in

509 order to examine the factors associated with broad scale variation in chromosome

510 inversion evolution. Many clades contain additional species that were not karyotyped, and

511 hence not included in the tree, yet these species may influence chromosomal evolution in

512 the focal taxa, e.g. through range overlap. To take this into account, I utilized phylogenies

513 from 54 published family-level studies in order to determine which non-karyotyped

514 species to include in clade level analyses (S5 Table). Clades were assigned based on the

515 following grouping criteria: the two most distantly related karyotyped species were less

516 than 15 million years diverged, member species' were the result of speciation within a

517 single geographic region (i.e. all clade members speciated in Australia), member species

518 were ecologically similar (i.e. finches, warblers, frugivores, nectarivores, or omnivores), a

519 comprehensive family level phylogeny exists to identify non-karyotyped member taxa, and

520 they encompassed at least three species including non-karyotyped taxa. After filtering 
521 based on the above criteria, 285 of 410 karyotyped species were assigned to 80 clades (S1,

522 S5 Tables).

523 I measured variation in karyotype evolution across passerine clades by counting the

524 total number of inversions that had fixed on each chromosome, summing over all branches

525 within the clade. I did not include inversion polymorphisms in this count unless the

526 ancestral conformation of the chromosome polymorphic for an inversion, determined in

527 Mesquite, was neither of the segregating forms. I calculated clade branch length as the sum

528 of branch lengths for species with centromere position scored at each of the 9 autosomes,

529 the Z, and W chromosomes. For example, if all species within a clade had complete

530 karyotype records (i.e. centromere position scored for all 11 chromosomes), the branch

531 length value of that clade was the sum of all branches multiplied by a factor of 11 . For

532 species missing data for a chromosome, the length of the branch leading to that species was

533 removed from the clade total according to the total number of missing chromosomes (i.e. if

534 a species was missing data at two chromosomes then $2 \times$ the branch length to that species

535 were subtracted from the clade total).

536 I collected range overlap, range size, and body mass data from the complete taxon

537 set for each clade (i.e. including both karyotyped and non-karyotyped species) in order to

538 evaluate the extent to which variation in demography (population size) and speciation

539 history (range overlap) has impacted inversion evolution (S5 Table). I extracted range data

540 for all species from natureserve.org using the programs Sp [76] and PBSmapping [77] in R.

541 I assigned each clade a range size value corresponding to the median range size $\left(\mathrm{km}^{2}\right)$ of all

542 member taxa. Median body mass (g) for each clade was calculated from Dunning [78]. I

543 used range size together with body mass in mixed models as proxies for population size 
544 based on the positive relationship between the geographic area a species occupies and its

545 nucleotide diversity [79-82] and the negative relationship generally observed between

546 body size and population density [83]. I assigned a range overlap score to each clade based

547 on the proportion of all species pairs whose ranges overlap by $>20 \%$ and/or are known to

548 hybridize in the wild [51]. I include hybridizing taxa together with taxa whose ranges are

549 sympatric because both imply there is at least the potential for gene flow between taxa.

550 Lastly, I considered a broad role for ecology on chromosome inversion evolution across

551 clades according to the feeding guild used when defining clades (i.e. clades defined as

552 comprising granivores, insectivores, frugivores, or ominvores; [33]).

553 In order to improve the interpretability of regression coefficients, the total number

554 of inversions, branch length, range size, and body mass were log transformed, range

555 overlap was arcsine square root transformed, and all variables were centered before

556 analysis [84]. I then evaluated the extent to which the number of inversions that had fixed

557 in each clade was associated with branch length, range overlap, range size, body mass, and

558 ecology using generalized least squares to take into account phylogenetic relationships

559 [85]. To do this, I used the NLME package in R [86], with the expected error covariance

560 matrix computed based on the phylogenetic distances between clades (S3 Fig.). To assess

561 the relative importance of each factor on the number of inversions fixed in each clade, I

562 compared all possible models and selected the best-fit model based on sample size-

563 corrected information criteria (AICc) using the R package MuMIn [50].

564

565 Chromosome Inversion Variation Between Sister Species 
566 I also considered the distribution of inversions between sister species, including both fixed

567 differences and inversions segregating in one taxon but not the other. I determined which

568 karyotyped species pairs were true sisters using the available phylogenetic literature (S6

569 Table). I considered a sister pair to hybridize if they had documented hybrid zones or

570 extensive natural hybridization where they co-occur [51]. In total, I identified 47 true

571 sisters with both species karyotyped, of which 12 are known to regularly hybridize in

572 nature (S6 Table).

$573 \quad$ For all 47 sister pairs, I calculated the number of inversion differences between

574 them, their time to common ancestry, average range size, range overlap, and whether they

575 are known to hybridize in the wild. Inversion differentiation was scored both as a binary

576 character (no inversions or at least one inversion difference) and as a count (total number

577 of inversion differences). Range overlap was evaluated as a binary character: no overlap or

578 some overlap. I only used this binary categorization because subdividing sisters who

579 overlapped in range into either parapatric ( $<20 \%$ overlap) or sympatric ( $>20 \%$ overlap)

580 bins did not improve the fit of any model or alter the results in any way. I used a linear

581 model to examine the interaction between the number of sister pair inversion differences

582 and each factor (age, range size, range overlap, and hybridization) after transforming the

583 continuous character data as described for analysis of clades. Lastly, I assessed whether

584 sister species with overlapping ranges, and the subset of sympatric sisters known to

585 hybridize, are more likely to differ by an inversion than allopatric sisters using $t$-tests.

586 Genetic distance is not time but rather an estimate of time, and one that can come

587 with substantial error. This error can diminish the true contribution of time and elevate the

588 importance of alternative factors [52]. A method to completely control for the potentially 
589 confounding influence of time is the use of species triplets [52-54]. A triplet consists of a

590 sister species pair (A, B) and a single outgroup taxon (0). Both sister taxa have by

591 definition been separated from the outgroup for the same length of time. If 0 overlaps B but

592 not $A$, then the presence of more inversion differences between 0 and $B$ than 0 and $A$ gives

593 strong support for a role of range overlap independent of time (see Fig. 4). I assembled a

594 set of species triplets from the phylogeny of karyotyped species and published phylogenies,

595 using the following criteria: both sister species A and B have been karyotyped, A and B are

596 allopatric, and B overlaps in range with 0 but species A does not. This resulted in just 5

597 triplets (S7 Table). I relaxed the criteria to allow 1) range overlap between A and B and 2)

598 range overlap between $A$ and $O$ so long as they were not sympatric (i.e. ranges overlapped

599 less than 20\%) and overlapped in range less than B and 0 . The average extent of range

600 overlap between species $A$ and 0 , when they did overlap, was $3 \times$ less than the extent of

601 range overlap between B and 0 (S7 Table). Nineteen triplets were present after applying

602 the relaxed filtering criteria (S7 Table).

603 I counted the number of inversions inferred to have occurred along the branches

604 leading to species A and B, respectively, based on the distribution of fixed inversions in the

605 complete karyotyped species phylogeny. I also included inversion polymorphisms found in

606 one but not the other taxon. I scored each triplet as follows: more inversions in A than B,

607 more inversions in B than A, or no difference in the number of inversions between A and B.

608 I evaluated the direction and significance of the relationship between range overlap and

609 inversion evolution across all triplets by applying a signed rank test to those sisters where

610 the number of inversions differed. 


\section{Genomic Distribution of Chromosome Inversions}

613 Inversion fixation models that depend heavily on mutational input (e.g. meiotic drive and

614 breakpoint selection) predict a strong correlation with range size but they also predict a

615 strong association with mutation rate. In a final analysis to examine the extent to which

616 inversion evolution is a mutation limited process, I examined the distribution of

617 chromosome inversions across the genome and evaluated the degree to which the number

618 of inversions fixed on a chromosome (S8 Table) was associated with four possible

619 mutagenic processes. First, if the mutation rate for inversions is constant per DNA base, the

620 number of inversions should be proportional to chromosome size. Second, because

621 inversions are derived from double-stranded meiotic breaks, the number of inversions on a

622 chromosome could best be predicted by its map length or GC content - features associated

623 with the number of cross-overs per chromosome $[87,88]$. Third, as inversion breakpoints

624 are often located in repeat-rich regions of chromosomes [43,44], I tested for an association

625 between the number of inversions and a chromosome's repeat density. Fourth, I asked if

626 the dynamics of inversion fixation on the sex chromosomes and the autosomes differ [25].

627 Mutation rates on the $\mathrm{Z}$ chromosome should be relatively high in birds because the $\mathrm{Z}$

628 spends ? of the time in males, however this mutational advantage needs to overcome the

629 fact that there are only $3 / 4$ as many copies of the $\mathrm{Z}$ as each of the autosomes $[89,90]$. In

630 contrast, the $\mathrm{W}$ chromosome should have a low mutation rate both because it spends all its

631 time in females and there are $1 / 4$ as many copies of the $\mathrm{W}$ as the autosomes.

632 Primary estimates of chromosome physical size, map length, and GC content were

633 derived from the collared flycatcher genome assembly and linkage map [44] and

634 chromosome repeat density was estimated from a RepeatMasker annotation of the zebra 
635 finch genome (http://www.repeatmasker.org; [55]). I use chromosome size and map

636 length data from the collared flycatcher but obtained identical results when analyses were

637 repeated using chromosome size and map distance data derived from zebra finch [42,56]

638 and hooded crow (Corvus cornix [91]; S10 Table). Comparative genomic studies indicate

639 that chromosome size (excluding the W chromosome), GC content, and repeat density are

640 conserved even between species in different avian orders $[44,45,92]$. While the

641 recombination landscape may have phylogenetic signal [93-95], recombination hotspots

642 are well maintained in passerines [58].

643 I used data from all 410 karyotyped species to examine the correlation between a

644 chromosome's inversion fixation rate and its physical size, GC content, repeat density, and

645 map length, using each chromosome as a replicate. In order to account for species with

646 missing data I use inversion fixation rate (total number of inversions fixed on a

647 chromosome divided by the combined branch length for all species with data for that

648 chromosome) rather than inversion number (S1 Table). Independent variables were log-

649 transformed. I evaluated support for alternative mutagenic hypotheses by comparing

650 between all possible linear models and selected the best-fit model using the R package

651 MuMIn [50]. Restricting the analysis to the 291 species with complete karyotype data (i.e.

652 documented centromere position for all 11 chromosomes) yielded a similar result (S10

653 Table). Finally, I tested for significant differences in the rate of inversion fixation between

654 the autosomes, $\mathrm{Z}$, and $\mathrm{W}$ chromosomes using the 80 independent passerine clades defined

655 above as replicates and paired $t$-tests.

\section{Acknowledgements}


658 I thank N.S. Bulatova, B.S.W. Chang, E.J. de Lucca, G. Semenov, P. Tang, I.M. Ventura, Y. Wu,

659 and the University of Chicago Library for their help in accessing cytological studies not

660 currently available online. I thank S.G. Dubay, T.D. Price, Supriya, and A.E. White for their

661 assistance with statistical analyses and figure aesthetics. Tissue materials for species

662 without data on GenBank came from the Kansas University Biodiversity Institute and

663 Natural History Museum. Thanks to M. Sorenson and C. H. Oliveros for sharing unpublished

664 phylogenetic results. A.E. Johnson provided original artwork of the Chloris greenfinches

665 used in Fig. 2. I am grateful to the assistance of T.D. Price for his helpful comments and

666 suggestions on multiple versions of this manuscript and to M. Przeworski for her feedback

667 on a single version. 


\section{References:}

669 1. Hoffmann AA, Rieseberg LH. Revisiting the impact of inversions in evolution: from population genetic markers to drivers of adaptive shifts and speciation?. Annual review of ecology, evolution, and systematics. 2008; 39: 21.

2. Faria R, Navarro A. Chromosomal speciation revisited: rearranging theory with pieces of evidence. Trends in ecology \& evolution. 2010; 25: 660-669. inversions at present and past pseudoautosomal boundaries in human sex chromosomes. Genome biology and evolution. 2009; 1: 56-66.

4. Wilson MA, Makova KD. Genomic analyses of sex chromosome evolution. Annual review of genomics and human genetics. 2009; 10: 333-354.

682

5. Wright AE, Harrison PW, Montgomery SH, Pointer MA, Mank JE. Independent stratum formation on the avian sex chromosomes reveals inter-chromosomal gene conversion and predominance of purifying selection on the W chromosome. Evolution. 2014; 68: 3281-95. Kronforst MR. Doublesex is a mimicry supergene. Nature. 2014; 507: 229-32.

7. Küpper C, Stocks M, Risse JE, dos Remedios N, Farrell LL, McRae SB, Morgan TC, Karlionova N, Pinchuk P, Verkuil YI, Kitaysky AS. A supergene determines highly divergent male reproductive morphs in the ruff. Nature genetics. 2015.

694

8. Lamichhaney S, Fan G, Widemo F, Gunnarsson U, Thalmann DS, Hoeppner MP, Kerje S, Gustafson U, Shi C, Zhang H, Chen W. Structural genomic changes underlie alternative reproductive strategies in the ruff (Philomachus pugnax). Nature genetics. 2016; 48: 84-8. A, Cheviron ZA, Warren WC, Gonser RA. Divergence and Functional Degradation of a Sex Chromosome-like Supergene. Current Biology. 2016. in the In (3R) Payne inversion polymorphism has shifted in the last 20 years in Australian Drosophila melanogaster populations. Molecular Ecology. 2005; 14: 851-8. 
12. Joron M, Frezal L, Jones RT, Chamberlain NL, Lee SF, Haag CR, Whibley A, Becuwe M, Baxter SW, Ferguson L, Wilkinson PA. Chromosomal rearrangements maintain a polymorphic supergene controlling butterfly mimicry. Nature. 2011; 477: 203-206.

13. Jones FC, Grabherr MG, Chan YF, Russell P, Mauceli E, Johnson J, Swofford R, Pirun M, Zody MC, White S, Birney E. The genomic basis of adaptive evolution in threespine sticklebacks. Nature. 2012; 484: 55-61.

720

14. Rieseberg LH. Chromosomal rearrangements and speciation. Trends in Ecology \& Evolution. 2001; 16: 351-358. reproductive isolation of species. Proceedings of the National Academy of Sciences. 2001; 98: 12084-12088.

16. Brown KM, Burk LM, Henagan LM, Noor MA. A test of the chromosomal rearrangement model of speciation in Drosophila pseudoobscura. Evolution. 2004; 58: 1856-1860.

\section{Ayala D, Guerrero RF, Kirkpatrick M. Reproductive isolation and local adaptation} quantified for a chromosome inversion in a malaria mosquito. Evolution. 2013; 67: 946958.

18. Fishman L, Stathos A, Beardsley PM, Williams CF, Hill JP. Chromosomal rearrangements and the genetics of reproductive barriers in Mimulus (monkey flowers). Evolution. 2013; 67: $2547-2560$.

19. King M. Species evolution: the role of chromosome change. Cambridge University Press; 1995.

20. Lande R. Effective deme sizes during long-term evolution estimated from rates of chromosomal rearrangement. Evolution. 1979: 234-251.

21. Lande R. The fixation of chromosomal rearrangements in a subdivided population with local extinction and colonization. Heredity. 1985; 54: 323-332.

22. Hedrick PW. The establishment of chromosomal variants. Evolution. 1981: 322-332.

23. Walsh JB. Rate of accumulation of reproductive isolation by chromosome rearrangements. American Naturalist. 1982: 510-532.

24. Spirito F. The role of chromosomal change in speciation. Endless forms: Species and speciation (DJ Howard and SH Berlocher, eds.). Oxford Univ. Press, Oxford, UK. 1998: 320329.

25. Hooper DM, Price TD. Rates of karyotypic evolution in Estrildid finches differ between island and continental clades. Evolution. 2015; 69: 890-903. 
26. Wesley CS, Eanes WF. Isolation and analysis of the breakpoint sequences of

758 chromosome inversion In (3L) Payne in Drosophila melanogaster. Proceedings of the National Academy of Sciences. 1994; 91: 3132-3136.

27. Puig M, Cáceres M, Ruiz A. Silencing of a gene adjacent to the breakpoint of a

762 widespread Drosophila inversion by a transposon-induced antisense RNA. Proceedings of the National Academy of Sciences of the United States of America. 2004; 101: 9013-9018.

28. White MJ. Chain processes in chromosomal speciation. Systematic Biology. 1978; 27:

766

29. King M. Species evolution: the role of chromosome change. Cambridge University Press; 1995.

30. Charlesworth D, Charlesworth B. Selection on recombination in clines. Genetics. 1979; 91: 581.

31. Kirkpatrick M, Barton N. Chromosome inversions, local adaptation and speciation.

Genetics. 2006; 173: 419-434.

32. Feder JL, Gejji R, Powell TH, Nosil P. Adaptive chromosomal divergence driven by mixed geographic mode of evolution. Evolution. 2011; 65: 2157-2170.

\section{Del Hoyo J, Elliott A, Christie D. Handbook of the birds of the world.}

34. Price TD, Hooper DM, Buchanan CD, Johansson US, Tietze DT, Alström P, Olsson U, Ghosh-Harihar M, Ishtiaq F, Gupta SK, Martens J. Niche filling slows the diversification of Himalayan songbirds. Nature. 2014; 509: 222-225.

35. Christidis L. Animal cytogenetics 4: Chordata 3 B: Aves. Gebrüder Borntraeger, Berlin, Germany. 1990.

794

795

36. Shields GF. Comparative avian cytogenetics: a review. Condor. 1982: 45-58.

798

37. Price T. Speciation in birds. Roberts and Co.; 2008.

38. Völker M, Backström N, Skinner BM, Langley EJ, Bunzey SK, Ellegren H, Griffin DK. Copy number variation, chromosome rearrangement, and their association with recombination during avian evolution. Genome research. 2010; 20: 503-511.

39. Stapley J, Birkhead TR, Burke T, Slate J. A linkage map of the zebra finch Taeniopygia guttata provides new insights into avian genome evolution. Genetics. 2008; 179: 651-667. 
800 40. Hansson B, Ljungqvist M, Dawson DA, Mueller JC, Olano-Marin J, Ellegren H, Nilsson JA.

801 Avian genome evolution: insights from a linkage map of the blue tit (Cyanistes caeruleus).

802 Heredity. 2010; 104: 67-78.

803

804

41. Aslam ML, Bastiaansen JW, Crooijmans RP, Vereijken A, Megens HJ, Groenen MA. A SNP

805 based linkage map of the turkey genome reveals multiple intrachromosomal

806

807 rearrangements between the turkey and chicken genomes. Bmc Genomics. 2010; 11: 647.

42. Backström N, Forstmeier W, Schielzeth H, Mellenius H, Nam K, Bolund E, Webster MT, Öst T, Schneider M, Kempenaers B, Ellegren H. The recombination landscape of the zebra finch Taeniopygia guttata genome. Genome research. 2010; 20: 485-495.

811

43. Skinner BM, Griffin DK. Intrachromosomal rearrangements in avian genome evolution: evidence for regions prone to breakpoints. Heredity. 2012; 108: 37-41.

814

44. Kawakami T, Smeds L, Backström N, Husby A, Qvarnström A, Mugal CF, Olason P, Ellegren H. A high-density linkage map enables a second-generation collared flycatcher genome assembly and reveals the patterns of avian recombination rate variation and chromosomal evolution. Molecular ecology. 2014; 23: 4035-4058. RW, Ödeen A. Comparative genomics reveals insights into avian genome evolution and adaptation. Science. 2014; 346: 1311-1120.

46. Prum R0, Berv JS, Dornburg A, Field DJ, Townsend JP, Lemmon EM, Lemmon AR. A comprehensive phylogeny of birds (Aves) using targeted next-generation DNA sequencing. Nature. 2015.

47. Claramunt S, Cracraft J. A new time tree reveals Earth history's imprint on the evolution of modern birds. Science Advances. 2015; 1: e1501005.

48. Yu, G. and T.T.Y. Lam. ggtree: a phylogenetic tree viewer for different types of tree annotations.

834

49. Jenks, G.F., 1967. The data model concept in statistical mapping. International yearbook of cartography, 7:186-190.

50. Bartoń K. MuMIn: multi-model inference. 2013. R package version; 1. 5.

841

842 Press; 2006. 
845 53. Noor MA. How often does sympatry affect sexual isolation in Drosophila?. The American 846 Naturalist. 1997; 149: 1156-1163.

847

848

849

850

851

852

853

854

855

856

857

858

859

860

861

862

863

864

865

866

867

868

869

870

871

872

873

874

875

876

877

878

879

880

881

882

883

884

885

886

887

888

889

890

54. Martin PR, Montgomerie R, Lougheed SC. Color patterns of closely related bird species are more divergent at intermediate levels of breeding-range sympatry. The American Naturalist. 2015; 185: 443-451.

55. Smit AF, Hubley R, Green P. 2010 RepeatMasker Open-3.0. URL: http://www. repeatmasker. org. 1996.

56. Warren WC, Clayton DF, Ellegren H, Arnold AP, Hillier LW, Künstner A, Searle S, White S, Vilella AJ, Fairley S, Heger A. The genome of a songbird. Nature. 2010; 464: 757-762.

57. Price TD, Bouvier MM. The evolution of F1 postzygotic incompatibilities in birds. Evolution. 2002; 56: 2083-2089.

58. Singhal S, Leffler EM, Sannareddy K, Turner I, Venn O, Hooper DM, Strand AI, Li Q, Raney B, Balakrishnan CN, Griffith SC. Stable recombination hotspots in birds. Science. 2015; 350: 928-932.

59. Payseur BA, Rieseberg LH. A genomic perspective on hybridization and speciation. Molecular ecology. 2016.

60. Weir JT, Price TD. Limits to speciation inferred from times to secondary sympatry and ages of hybridizing species along a latitudinal gradient. The American Naturalist. 2011; 177: 462-469.

61. Price TD. The roles of time and ecology in the continental radiation of the Old World leaf warblers (Phylloscopus and Seicercus). Philosophical Transactions of the Royal Society of London B: Biological Sciences. 2010; 365: 1749-1762.

62. Kolaczkowski B, Kern AD, Holloway AK, Begun DJ. Genomic differentiation between temperate and tropical Australian populations of Drosophila melanogaster. Genetics. 2011; 187: 245-260.

63. Rane RV, Rako L, Kapun M, Lee SF, Hoffmann AA. Genomic evidence for role of inversion 3RP of Drosophila melanogaster in facilitating climate change adaptation. Molecular ecology. 2015; 24: 2423-2432.

64. Ayala D, Ullastres A, González J. Adaptation through chromosomal inversions in Anopheles. Frontiers in Genetics. 2014; 5: 129.

65. Nishikawa H, Ijima T, Kajitani R, Yamaguchi J, Ando T, Suzuki Y, Sugano S, Fujiyama A, Kosugi S, Hirakawa H, Tabata S. A genetic mechanism for female-limited Batesian mimicry in Papilio butterfly. Nature genetics. 2015; 47: 405-409. 
891 66. Miller CT, Glazer AM, Summers BR, Blackman BK, Norman AR, Shapiro MD, Cole BL, 892 Peichel CL, Schluter D, Kingsley DM. Modular skeletal evolution in sticklebacks is controlled 893 by additive and clustered quantitative trait loci. Genetics. 2014; 197: 405-420.

894

67. Dean R, Harrison PW, Wright AE, Zimmer F, Mank JE. Positive selection underlies Faster-Z evolution of gene expression in birds. Molecular biology and evolution. 2015; 32:

897

898 2646-2656.

68. Levan A, Fredga K, Sandberg AA. Nomenclature for centromeric position on

901

902 chromosomes. Hereditas. 1964; 52: 201-220.

903

904

905

906

69. Krasikova A, Daks A, Zlotina A, Gaginskaya E. Polymorphic heterochromatic segments in Japanese quail microchromosomes. Cytogenetic and genome research. 2009; 126: 148-155.

70. Zlotina A, Galkina S, Krasikova A, Crooijmans RP, Groenen MA, Gaginskaya E,

907 Deryusheva S. Centromere positions in chicken and Japanese quail chromosomes: de novo centromere formation versus pericentric inversions. Chromosome research. 2012; 20:

909 1017-1032.

71. Marshall OJ, Chueh AC, Wong LH, Choo KA. Neocentromeres: new insights into centromere structure, disease development, and karyotype evolution. The American Journal of Human Genetics. 2008; 82: 261-282.

72. Drummond AJ, Rambaut A. BEAST: Bayesian evolutionary analysis by sampling trees. BMC evolutionary biology. 2007; 7: 214.

73. Posada D. jModelTest: phylogenetic model averaging. Molecular biology and evolution. 2008; 25: 1253-1256.

\section{Rambaut A, Suchard MA, Xie D, Drummond AJ. Tracer v1.6.}

75. Maddison WP, Maddison DR. Mesquite: a modular system for evolutionary analysis.

76. Pebesma EJ, Bivand RS. sp: classes and methods for spatial data. R package version 0.944.

77. Schnute JT, Boers N, Haigh R, Couture-Beil A. PBSmapping: PBS Mapping 2.59. R package version. 2008; 2: 59.

78. Dunning JB. Handbook of avian body masses. CRC, Boca Raton. 1993.

933

934

935

79. Nevo E, Beiles A, Ben-Shlomo R. The evolutionary significance of genetic diversity: ecological, demographic and life history correlates. Springer Berlin Heidelberg; 1984. 
81. Balakrishnan CN, Edwards SV. Nucleotide variation, linkage disequilibrium and founder-facilitated speciation in wild populations of the zebra finch (Taeniopygia guttata). Genetics. 2009; 181: 645-660.

82. Leffler EM, Bullaughey K, Matute DR, Meyer WK, Segurel L, Venkat A, Andolfatto P, Przeworski M. Revisiting an old riddle: what determines genetic diversity levels within species?. PLoS Biol. 2012; 10: e1001388.

83. White EP, Ernest SM, Kerkhoff AJ, Enquist BJ. Relationships between body size and

84. Schielzeth H. Simple means to improve the interpretability of regression coefficients. Methods in Ecology and Evolution. 2010; 1: 103-113.

85. Grafen A. The phylogenetic regression. Philosophical Transactions of the Royal Society of London. Series B, Biological Sciences. 1989; 326: 119-157.

86. Pinheiro J, Bates D, DebRoy S, Sarkar D, Team RC. nlme: Linear and nonlinear mixed effects models. 2012. R package version; 3: 103.

87. Baudat F, de Massy B. Regulating double-stranded DNA break repair towards crossover or non-crossover during mammalian meiosis. Chromosome research. 2007; 15: 565-577.

88. de Massy B. Initiation of meiotic recombination: how and where? Conservation and specificities among eukaryotes. Annual review of genetics. 2013; 47: 563-599.

89. Ellegren H, Fridolfsson AK. Male-driven evolution of DNA sequences in birds. Nature genetics. 1997; 17: 182-184.

90. Axelsson E, Smith NG, Sundström H, Berlin S, Ellegren H. Male-biased mutation rate and divergence in autosomal, Z-linked and W-linked introns of chicken and turkey. Molecular Biology and Evolution. 2004; 21: 1538-1547.

91. Poelstra JW, Vijay N, Bossu CM, Lantz H, Ryll B, Müller I, Baglione V, Unneberg P, Wikelski M, Grabherr MG, Wolf JB. The genomic landscape underlying phenotypic integrity in the face of gene flow in crows. Science. 2014; 344: 1410-1414.

92. Ellegren H. The evolutionary genomics of birds. Annual Review of Ecology, Evolution, and Systematics. 2013; 44: 239-259.

93. Dumont BL, Payseur BA. Evolution of the genomic rate of recombination in mammals. Evolution. 2008; 62: 276-294.

94. Dumont BL, Payseur BA. Evolution of the genomic recombination rate in murid rodents. Genetics. 2011; 187: 643-657. 
bioRxiv preprint doi: https://doi.org/10.1101/053371; this version posted May 14,2016. The copyright holder for this preprint (which was not certified by peer review) is the author/funder, who has granted bioRxiv a license to display the preprint in perpetuity. It is made available under aCC-BY-NC-ND 4.0 International license.

983

984 95. Smukowski CS, Noor MA. Recombination rate variation in closely related species.

985 Heredity. 2011; 107: 496-508. 


\section{Supporting Information}

987 S1 Fig. Phylogenetic distribution of fossil calibrations. Calibration nodes numbered

988 following S4 Table and labeled (red circles). Species included solely for calibration

989 purposes colored red.

990 S2 Fig. Pericentric inversion fixation rate variation across passerine birds. The

991 phylogenetic relationships between the 410 karyotyped species in this study are presented

992 in a time-dated maximum clade credibility tree. Branches are color-coded according to the

993 inferred rate of pericentric inversion fixation using the R package ggtree[48]. Rates are

994 partitioned according to the Jenks natural breaks method where variance within bins is

995 minimized, while variance between bins is maximized [49].

996 S3 Fig. Phylogeny used in phylogenetic generalized least squares for clade level

997 analysis. Branch lengths are proportional to time and were used to compute the expected

998 error covariance matrix between clades for phylogenetic generalized least-squares. Species

999 identity for the 285 taxa assigned to clades is given in S1 Table. Clade information

1000 (inversions, branch length, range size, range overlap, ecology, etc.) are given in S4 Table.

1001 S1 Table. Chromosome character state matrix with references.

1002 S2 Table. Chromosome rearrangement polymorphisms.

1003 S3 Table. Loci used in phylogenetic analyses.

1004 S4 Table. Fossil calibration set with references.

1005 S5 Table. Clade data.

1006 S6 Table. Sister species data.

1007 S7 Table. Species triplet data.

1008 S8 Table. Genomic distribution of inversions across 80 passerine clades. 
bioRxiv preprint doi: https://doi.org/10.1101/053371; this version posted May 14, 2016. The copyright holder for this preprint (which was not certified by peer review) is the author/funder, who has granted bioRxiv a license to display the preprint in perpetuity. It is made available under aCC-BY-NC-ND 4.0 International license.

1009 S9 Table. Model comparison results for clade and sister species analyses.

1010 S10 Table. Model comparison results for genomic distribution of inversions. 


\section{Passerine Families}

I: Eurylamidae $(\mathrm{I}, \mathrm{I})$

2: Furnariidae $(2,2)$

3:Thamnophilidae $(4,9)$

4: Cotingidae $(I, 3)$

5:Tityridae $(1,2)$

6: Tyrannidae $(13,32)$

7:Aegithinidae $(1,0)$

8:Tephrodornithidae $(1,2)$

9: Campephagidae $(3,9)$

10: Oriolidae $(3,2)$

II:Vireonidae $(4,2)$

12: Dicruridae $(2,0)$

13: Monarchidae $(\mathrm{I}, \mathrm{I})$

14: Laniidae $(8,13)$

15: Corvidae $(15,21)$

16: Picathartidae $(1,4)$

17: Remizidae $(1,2)$

18: Paridae $(8,14$

19:Alaudidae $(6,9)$

20: Locustellidae $(4,8)$

21:Acrocephalidae $(5,10)$

22: Hirundinidae $(8,13)$

23: Cisticolidae $(2,5)$

24: Pycnonotidae $(8, \mathrm{II})$

25: Aegithalidae $(3,8)$

26: Cettidae $(\mathrm{I}, \mathrm{I})$

27: Phylloscopidae $(9,21)$

28: Sylviidae $(5,10)$

29: Zosteropidae $(5,3)$

30:Timaliidae $(3,2)$
3I: Pellorniidae $(3,3)$

32: Leiothrichidae $(14,28)$

33: Regulidae $(1,7)$

34: Bombycillidae $(3,0)$

35: Sittidae $(3,6)$

36: Certhiidae $(1,2)$

37: Polioptilidae $(I, 2)$

38: Troglodytidae $(3,5)$

39: Cinclidae (I, I)

40: Mimidae $(3,6)$

4I: Sturnidae $(8,7)$

42:Turdidae $(20,28)$

43: Muscicapidae $(35,77)$

44: Nectariniidae $(1,2)$

45: Chloropseidae $(2,2)$

46: Peucedramidae $(1,4)$

47: Prunellidae $(2,0)$

48: Ploceidae $(3,0)$

49: Estrildidae $(34,83)$

50: Passeridae $(7,19)$

51: Motacillidae $(8,15)$

52: Fringillidae $(21,40)$

53: Cardinalidae $(7,5)$

54:Thraupidae $(45,52)$

55: Parulidae $(6,2)$

56: Icteriidae $(1,3)$

57: Icteridae $(9,8)$

58: Emberizidae $(17,55)$

59: Passerellidae $(22,38)$

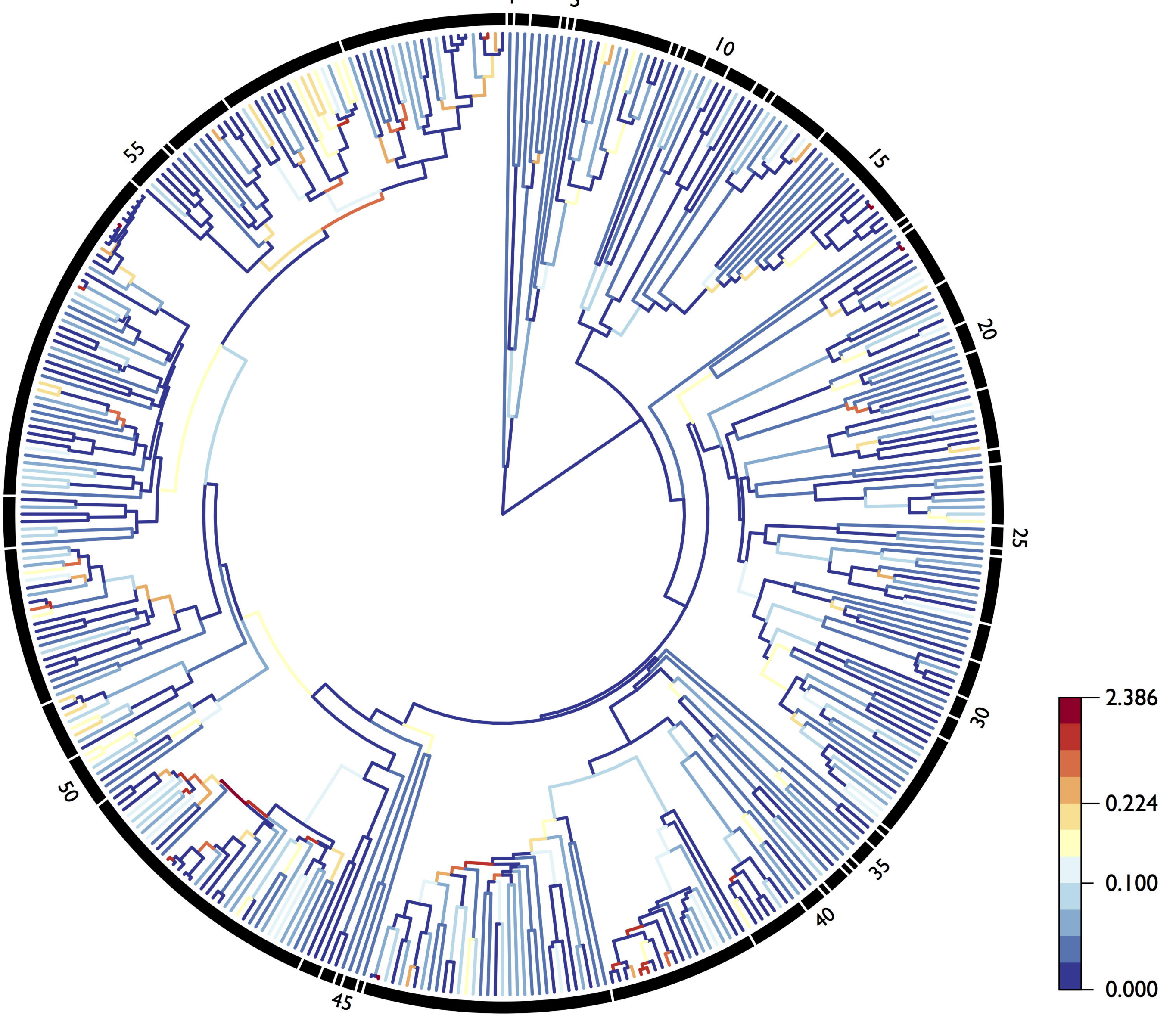





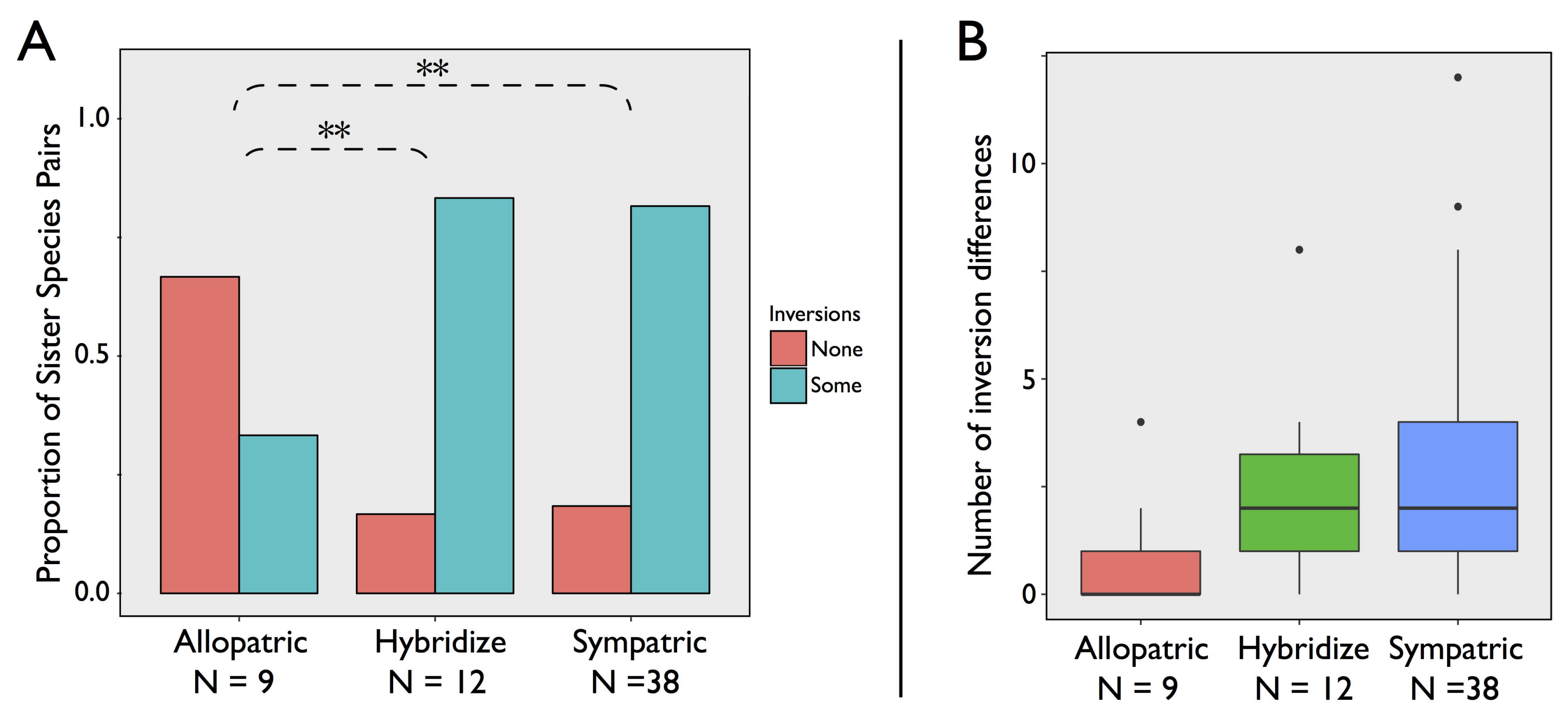



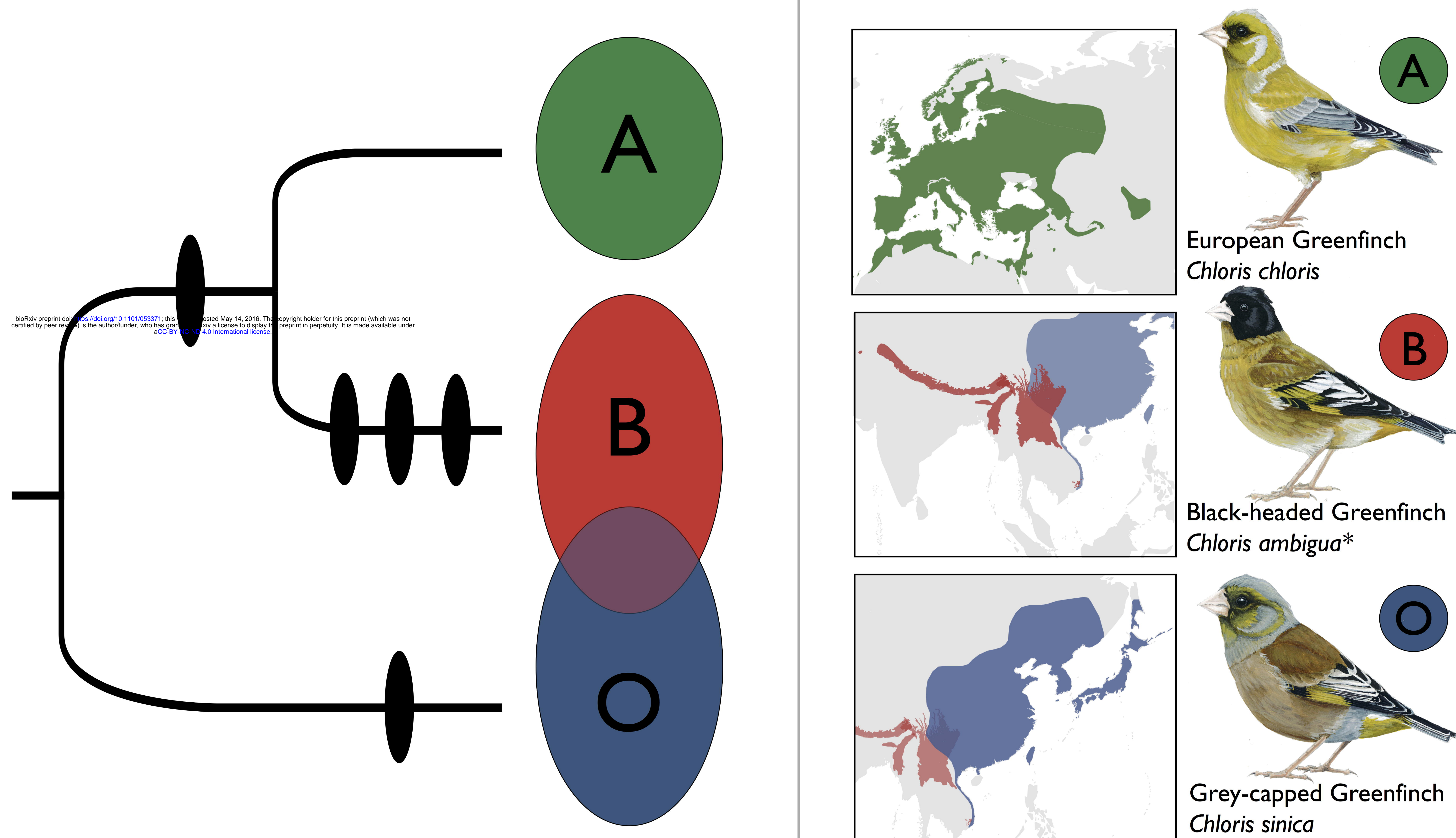

European Greenfinch

Chloris chloris
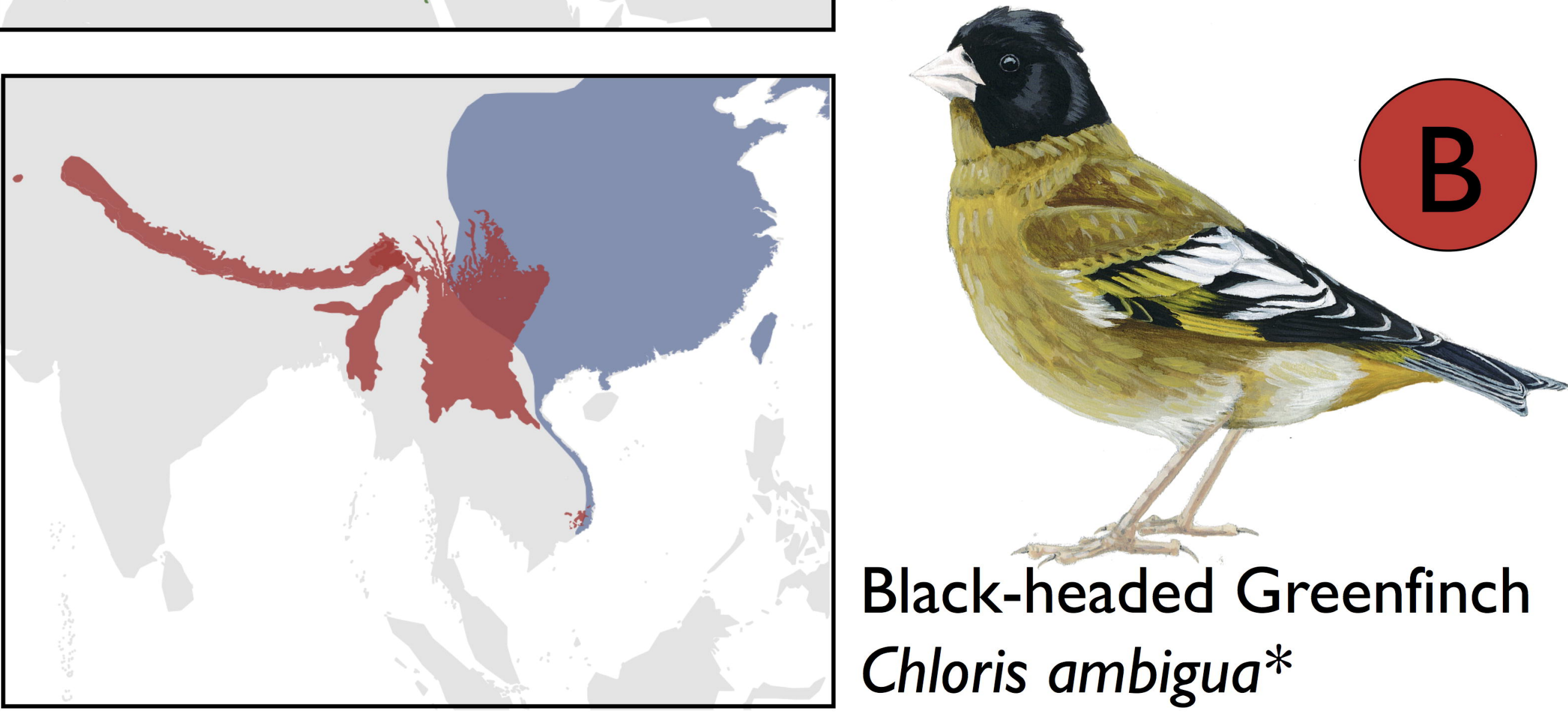

Black-headed Greenfinch

Chloris ambigua*
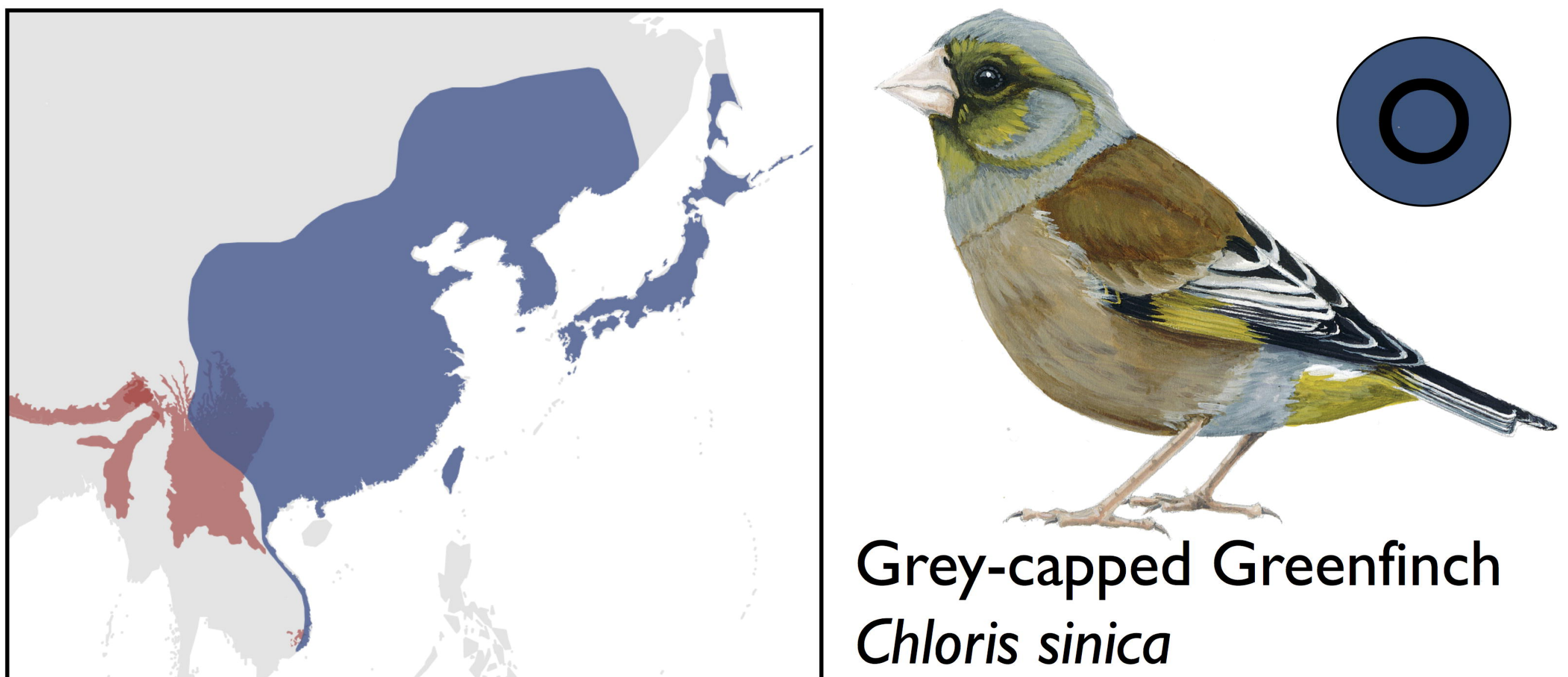

Grey-capped Greenfinch Chloris sinica 


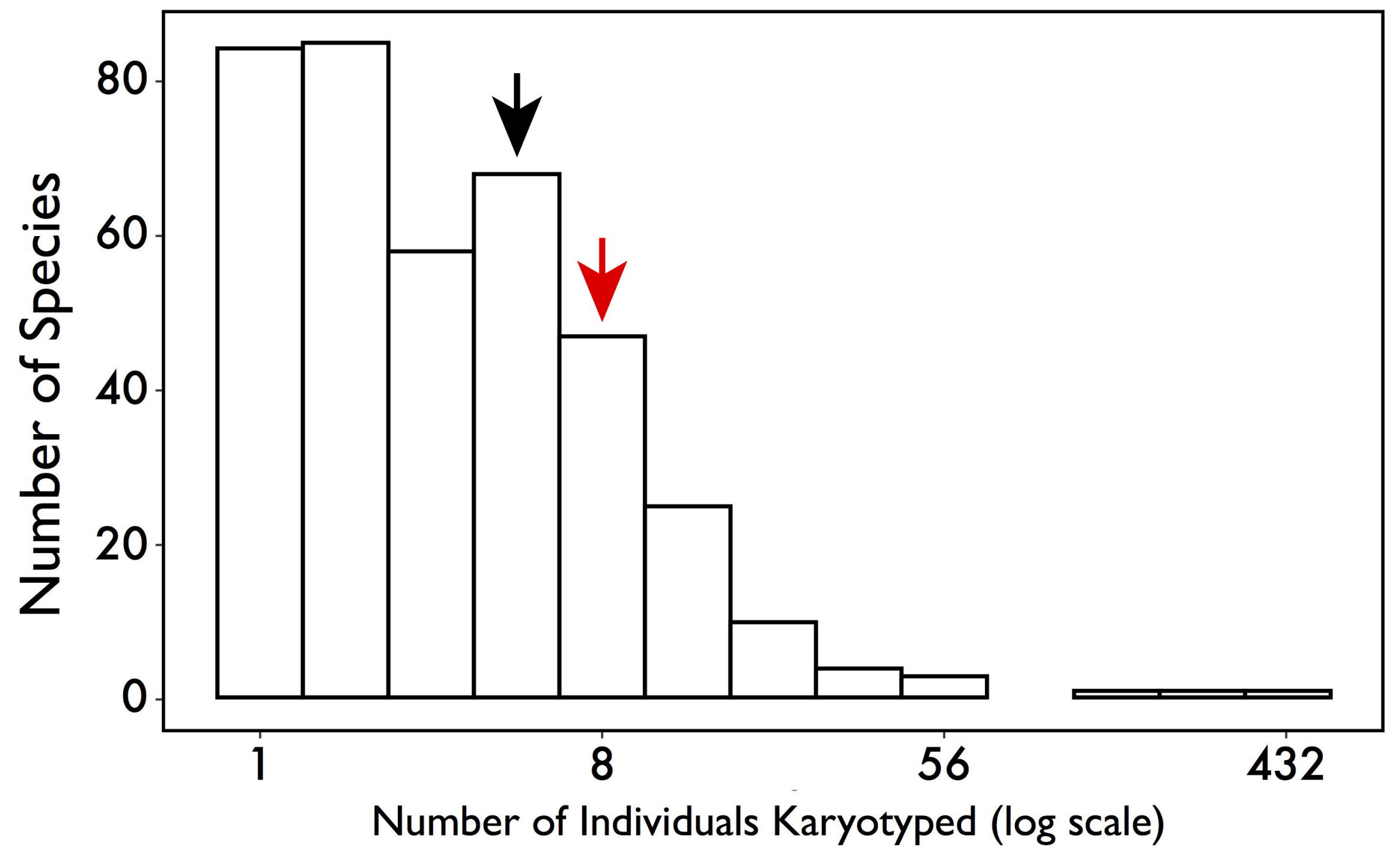

